\title{
Health-Related Quality of Life, Subjective Health Complaints, Psychological Distress and Coping in Pakistani Immigrant Women With and Without the Metabolic Syndrome
}

\author{
The InnvaDiab-DEPLAN Study on Pakistani Immigrant Women Living \\ in Oslo, Norway
}

\author{
Victoria Telle Hjellset • Camilla M. Ihlebæk • \\ Benedikte Bjørge • Hege R. Eriksen • \\ Arne T. Høstmark \\ Published online: 9 November 2010 \\ (C) The Author(s) 2010. This article is published with open access at Springerlink.com
}

\begin{abstract}
The increasingly high number of immigrants from South-East Asia with The Metabolic Syndrome (MetS) is an important challenge for the public health sector. Impaired glucose is essential in MetS. The blood glucose concentration is not only governed by diet and physical activity, but also by psychological distress which could contribute to the development of MetS. The aim of this study is to describe health-related quality of life, subjective health complaints (SHC), psychological distress, and coping in Pakistani immigrant women, with and without MetS. As a part of an randomized controlled intervention study in Oslo, Norway, female Pakistani immigrants $(n=198)$ answered questionnaires regarding health related quality of life, SHC, psychological distress, and coping. Blood variables were determined and a standardized oral glucose tolerance test was performed. The participants had a high score on SHC and psychological distress. About $40 \%$ of the participants had MetS, and this group showed significantly lower general health, lower
\end{abstract}

V. T. Hjellset $(\bowtie) \cdot$ A. T. Høstmark

Institute of General Practice and Community Medicine, University of Oslo, Blindern, Box 1130, 0318 Oslo, Norway

e-mail: v.t.hjellset@medisin.uio.no

V. T. Hjellset · C. M. Ihlebæk · H. R. Eriksen

Uni Health, University of Bergen, Bergen, Norway

C. M. Ihlebæk

Research group for Nature, Health and Quality of Life, IHA,

University of Life Sciences (UMB), Ås, Norway

B. Bjørge

Department of Nutrition, University of Oslo, Oslo, Norway

H. R. Eriksen

Faculty of Psychology, University of Bergen, Bergen, Norway physical function, and more bodily pain, than those without MetS. Those with MetS also had more SHC, depressive symptoms, higher levels of somatisation, and scored significantly lower on the coping strategy of active problem solving. Pakistani immigrant women seem to have a high prevalence of SHC and psychological distress, especially those with MetS.

Keywords Pakistani immigrant women - Immigration · Psychological distress $\cdot$ Coping $\cdot$ Metabolic syndrome

\section{Introduction}

The aim of the present work was to investigate the occurrence of the metabolic syndrome (MetS) and psychological and health related variables in a group of Pakistani immigrant women living in Oslo, Norway.

Every year more than 700 million people cross national borders [1], and the number of immigrants into developed countries is accelerating. This alteration in the population represents new and important challenges for the public health sector. One such challenge is an increase in Type 2 diabetes (T2D). The prevalence of T2D is high among immigrants [2-6], and especially immigrants from SouthAsia are at higher risk of developing T2D [7]. In Norway, in 2005, the prevalence of T2D among immigrants from the Middle East and South Asia was found to be as high as 36\% in the age group of 40-59 years, the group of immigrants from Pakistan, have the highest prevalence of T2D [7].

Metabolic disturbances, such as insulin resistance, accompanied by elevated plasma levels of glucose and free fatty acids, disturbances in the serum lipoproteins, elevated blood pressure and central obesity are risk factors for T2D. 
This clustering of risk factors is referred to as MetS [8]. The prevalence of MetS is higher among adult immigrants from the South Asian origins than for their Norwegian counterparts $[9,10]$. The pattern is similar in Sweden [11].

Ethnicity-related differences in the prevalence of MetS may be attributed to genetic and environmental factors [12]. Conceivably, immigrants that are influenced by a new environment, and adapting to a Western lifestyle, may engage in negative behavioural changes such as inactivity [13] and an unhealthy diet [14]. Immigrants from nonWestern countries are over-represented in low socio-economic status (SES) groups in Norway [15]. Low SES is an important risk factor for poor mental health [16, 17], and immigrants from low-income countries have higher odds of experiencing psychological distress due to pre- or postmigration factors [17-19].

Therefore, Pakistani immigrant women living in Norway may have an increased risk for developing MetS, related both to genetics, environment/lifestyle and to psychosocial factors. Indeed, a new life situation may represent serious challenges to their mental and somatic health. Within terms and concepts from the Cognitive Activation Theory of Stress "CATS" [20], their health may also be affected if they fail to develop a positive expectancy to their abilities to face the challenges they are exposed to in their new environment. According to CATS, this may lead to health challenges through two main pathways, a pathophysiological pathway and through behavioural mechanisms. When exposed to threats, demands, or challenges, people have different expectations on how they will be able to handle the situation. The stress response depends on these expectancies. Based on reinforcement contingencies and resources, the individual learns either positive response outcome expectancies (the CATS definition of coping) [20], or that nothing helps (no response outcome expectancy), or that everything goes wrong (negative response outcome expectancy) when faced with new demands. High levels of coping are associated with high social position and low stress values [21].

The pathophysiological pathway is followed when the individual does not develop an expectancy to cope with the challenges she is faced with. Whenever an individual is faced with demands and challenges, a normal and healthy stress response or activation will occur. This activation is the normal arousal response, which influences endocrine, autonomic, and immunological functions. This may be measured within the Hypothalamic Pituitary Adrenal-system. When the stress response is sustained somatic pathology may develop. Relevant for the risk of MetS is the sustained stress activation, which may increase the blood glucose concentration through stimulation of hepatic glycogenolysis. Stress activation may also enhance adipose tissue lipolysis, so as to increase plasma free fatty acids and triglyceride, and decrease the HDL cholesterol concentration [22]. Conceivably, therefore, stress activation may be associated with MetS. It seems that even slight fluctuations in blood sugar may harm endothelial cells, and sustained activity of the sympathetic nervous system have been shown to negatively influence the concentration of serum lipids [23].

The behavioural pathway is complex and with many effects. The lack of trust in ones own coping abilities is supposed to be an important explanatory factor for the individual development of SES [21]. When an individual has learned that whatever she or he is doing, the probability of success is low, it may be hard to be motivated to participate in healthy behaviour changes and acquire new life styles [21, 24]. Therefore, it is not only lack of education, lack of understanding the Norwegian language, and unfamiliar food supplies that explain the high prevalence of overweight in the immigrant Pakistani women in Norway [25]. Even if we reach out with information on diet and physical activity, there may also be a problem of motivation to invest in behavioural change and new habits. Finally, the lack of positive expectancies associated with lack of coping, and feelings of helplessness and hopelessness, is also associated with a high level of ordinary, SHC, like tiredness, muscle pain, and mood changes $[20,26,27]$.

Thus, the diagnosis of T2D, its treatment and its complications are closely related to the level of blood glucose, which increases and decreases as a result of physical activity and food intake, but may also be strongly influenced by psychological stress and coping. Accordingly, psychological stress could affect blood glucose regulation and thereby contribute to the development of MetS [28]. Our hypothesis is therefore that there is a high prevalence of MetS and psychological distress in Pakistani immigrants in Oslo, and that the prevalence might be higher in women with MetS.

\section{Methods}

This is a descriptive cross-sectional study where data are collected as part of a randomized controlled trial (The InnvaDiab DE-PLAN study) in Oslo. Baseline data were collected from April 2006 to July 2007.

\section{Participants}

One hundred and ninety eight female immigrants born in Pakistan were included in the study, mean age 41.2 years (95\% CI 40-42.3). Two hundred and forty five women were invited to the study. Of these, 47 were not included 
due to the inclusion/exclusion criteria or lack of interest. None of the participants were aware of having T2D before the intervention started. The inclusion criteria were: women age 25 years or older born in Pakistan living in Norway with Pakistani parents. The exclusion criteria were: a history of T2D for more than 6 months, and the following diagnoses from ICPC-2 (International Classification of Primary Care, ICPC-2) [29]; K29 (Cardiovascular symptoms or complaints), K84 (Heart disease), K99 (Cardiovascular disease), close relatives (daughter, sister, mother, sister-in-law, mother-in-law) included in the project, pregnancy, or not physically able to walk for $1 \mathrm{~h}$. Two women were excluded immediately after baseline; one because she was younger than 25 , and one because one of her parents was German.

\section{Recruitment}

Recruitment was done in a local community where approximately $40 \%$ of the population are immigrants, and where systematic diabetes intervention had never been performed. The participation rate in health trials has often been low among South Asian immigrants [30]. Therefore a multi-strategic recruitment with emphasis on personal contact was used to recruit Pakistani women as suggested by Hussain-Gambles et al. [31]. The recruitment is described in detail in Hjellset et al. [25]. The demographic and social profiles of the population were studied, and representative community members were consulted to provide assistance in the study. The eligibility criteria were set as widely as possible (25).

\section{Data Collection and Measures}

The International Diabetes Federation (IDF) definition of the metabolic syndrome of those from South and South-East Asian are; central obesity (defined as waist circumference) $\geq 80 \mathrm{~cm}$, plus any two of the following four factors: raised triglycerides; $\geq 1.7 \mathrm{mmol} / \mathrm{l}$, reduced HDL-cholesterol $<1.29$ $\mathrm{mmol} / \mathrm{l}$ in females, raised blood pressure; systolic BP $\geq 130$ or diastolic $\mathrm{BP} \geq 85 \mathrm{mmHg}$, or impaired fasting glycaemia (IFG); fasting plasma glucose $\geq 5.6 \mathrm{mmol} / 1$ [3-5].

All participants went through a comprehensive baseline screening. To determine metabolic syndrome, venous blood samples were drawn from an antecubital vein, and a standardized oral glucose tolerance test (OGTT) was performed, i.e. $75 \mathrm{~g}$ glucose in $200 \mathrm{ml}$ water was ingested and blood glucose was determined at time zero and after $2 \mathrm{~h}$. The OGTT was not performed if the fasting glucose value was $8 \mathrm{mmol} / \mathrm{l}$ or higher. In addition weight, height and waist circumference were measured. This is described in detail in Hjellset et al. [25].
Questionnaires

During the 2-h OGTT, trained bicultural and multilingual study personnel filled out all questionnaires during face-toface interviews. All interviewers had sufficient knowledge of Urdu, Punjabi, Norwegian, and English. The interviews were held in the preferred language of each participant. To ensure that all study personnel asked the question in the same way we regularly had a third person to observe the interviews.

The questionnaires covered a broad range of factors, including demographic variables, physical fitness, healthrelated quality of life, SHC, psychological distress, and coping.

\section{Health-Related Quality of Life}

Health-related quality of life was measured by the generic health status measure SF-36 [29-32]. The SF-36 measures eight of the most commonly used dimensions in health surveys, during the last 4 weeks [32]. The eight multi-item scales include: physical functioning (10 items), role limitations due to physical health (four items), bodily pain (two items), general health (five items), vitality/energy/fatigue (four items), social functioning (two items), role limitations due to emotional problems (three items), and mental health (five items). The SF-36 scales were transformed according to published scoring procedures, into a scale ranging from 0 (poor health) to 100 (good health). The SF-36 questionnaire has been tested and has satisfactory validity and reliability on the ethnic Norwegian population [33, 34], and for Asians immigrants [34], but has not been tested in Pakistani immigrants in Norway.

We included the scale of general health from the SF-36 [35]. This scale was constructed from a combination of the general questions on self-rated health together with questions about whether the participants believe that their health is going to become better or worse.

To assess well-being, a global measure of well-being called "ladder of life" was used [36]. The participants made a mark on a ladder with 10 steps, the highest representing "best possible life" and the lowest "worst possible life", at the level that they estimated corresponded to the value of their life. This questionnaire is tested for validity and reliability in a global American population [36], but not on Pakistani immigrants.

\section{Subjective Health Complaints}

Subjective health complaints (SHC) were measured with 29 items on subjective somatic and psychological complaints experienced during the last 30 days, using the SHC inventory. Severity was scored on a four-point scale, from 0 (no 
complaints) to 3 (severe complaints). Five factors are usually reported [37]: musculoskeletal complaints (headache, neck pain, shoulder pain, pain in arms, pain in upper back, low back pain, and leg pain), "pseudoneurological" complaints (extra heartbeats, heat flushes, sleep problems, tiredness, dizziness, anxiety, and sadness/depression), gastrointestinal complaints (heartburn, stomach discomfort, ulcer/non-ulcer dyspepsia, stomach pain, gas discomfort, diarrhoea, and constipation), allergic complaints (asthma, breathing difficulties, eczema, allergies, and chest pain), and flu (cold, flu, and cough). In addition, a total sum-score was calculated. In this study, responses to each complaint were categorized into absent (score 0) or present (score 1-3), to calculate the prevalence of each complaint. The questionnaire has been tested and has satisfactory validity and reliability on the ethnic Norwegian population [37], but has not been tested in Pakistani. There has been studies using SHC in both Maasais [38] and Mangyan (from the Puerto Galera area) [39] that shows great similarity in spite of very different cultures.

\section{Psychological Distress}

The Hopkins Symptom Checklist (HSCL), a 25-items questionnaire, was used to register psychological distress as experienced last 14 days [40, 41]. The questionnaire has been tested and has satisfactory validity and reliability on the ethnic Norwegian population [42], but has not been tested in Pakistani or other ethnic populations, although it has been used on Pakistani immigrants in Norway [17]. Lee and coworkers [43] concludes that interrater reliability, and testretest reliability of HSCL, is good for the host population in Tanzania, even if there could be some modification of the scale in cross-cultural settings. Each item is rated on a 4point scale from 1 (not bothered) to 4 (extremely bothered). Sub-scores (mean) of depression, anxiety, and somatisation were calculated. In addition a total-score (mean) was calculated. A cut-off point of 1.75 on the total score is usually used to identify patients with severe psychological distress ("psychiatric cases"), and larger than 1.75 on the depression score is labelled as "depressive". Even if HSCL-25 measure both depression and anxiety, the reliability and validity is found to be better on depression than anxiety [44].

\section{Coping}

Coping was measured using the Utrecht Coping List (UCL) $[45,46]$. UCL consists of 47 statements regarding how the respondent will react when facing a problem. The questionnaire has satisfactory reliability and validity in a large population based study on ethnic Norwegian [45]. Each statement is scored on 4 point scale, ranging from 1 (never/ seldom) to 4 (very often). The score (sum) for seven different coping strategies are usually reported, where 'active problem solving' is the strategy related to positive outcome expectancies defined in CATS.

\section{Physical Fitness}

Physical fitness was measured by the short version of the "International physical activity questionnaire" (IPAQ) [35]. IPAQ is an instrument for monitoring of physical activity and inactivity. The question "how will you describe your physical fitness?" was used to answer how they describe their physical fitness. The questionnaire has satisfactory reliability and validity for national and regional prevalence studies in fourteen different countries from all over the world from Sweden to Guatemala, in both urban and rural locations [35].

\section{Sample Size}

The sample size was calculated on the basis of a presumed $10 \%$ reduction on fasting and $2 \mathrm{~h}$ glucose, a significance level of $5 \%$, and a power of $80 \%$, a sample size of 82 patients per group was necessary, given an anticipated dropout rate of $15 \%$.

\section{Statistics}

All analyzes were carried out with SPSS, version 15.0. Differences between groups were evaluated by independent samples $t$ test and ANOVA, using Bonferroni correction for multiple comparisons, and Chi-square tests. The significance level was set to $P<0.05$, unless otherwise stated.

\section{Ethics Approval}

The study was approved by the Norwegian Ethics Committee for Medical Research, Health Region South, and performed according to the Helsinki Declaration. The participants received written and oral information in their mother tongue. All information from the participants was treated strictly confidential, and the participants gave their written consent to the project before the intervention started.

\section{Results}

The participants were 25-63 years old (Table 1). They had lived in Norway for approximately 20 years. 23\% described their understanding of the Norwegian language as good. Their mean educational level was low, and they lived in households with an average of 5.5 persons (Table 1).

About $41 \%(\mathrm{n}=81)$ of the participants had the complete MetS, and they were approximately 3 years older than those without the syndrome $(P<0.001)$ (Table 1$)$. 
Table 1 Descriptive data for the total group of Pakistani immigrant women, and in participants without and with the metabolic syndrome (MetS)

\begin{tabular}{|c|c|c|c|c|}
\hline & $\begin{array}{l}\text { Total } \\
(\mathrm{n}=198)\end{array}$ & $\begin{array}{l}\text { Without MetS } \\
(\mathrm{n}=113 / 194)\end{array}$ & $\begin{array}{l}\text { With MetS } \\
(\mathrm{n}=81 / 194)\end{array}$ & $P$-value \\
\hline Age & $41.2(8.1)$ & $39.8(7.5)$ & $43.1(8.6)$ & 0.005 \\
\hline Years of education & $9.1(4.5)$ & $9.5(4.5)$ & $8.5(4.5)$ & 0.120 \\
\hline Years living in Norway & $19.3(5.7)$ & $17.6(5.3)$ & $20.9(5.7)$ & 0.093 \\
\hline Persons in household & $5.5(1.8)$ & $5.5(1.6)$ & $5.6(2.1)$ & 0.668 \\
\hline Number of children & $3.5(1.5)$ & $3.4(1.4)$ & $3.6(1.7)$ & 0.535 \\
\hline Norwegian language skills ${ }^{\mathrm{b}}$ & $3.3(1.2)$ & $3.3(1.2)$ & $3.3(1.1)$ & 0.996 \\
\hline $\operatorname{BMI}\left(\mathrm{kg} / \mathrm{m}^{2}\right)$ & $29.7(5.4)$ & $28.3(5.5)$ & $31.2(5.0)$ & $<0.001$ \\
\hline Waist circumference $(\mathrm{cm})$ & $96.0(12.5)$ & $93.1(11.6)$ & $100.0(12.7)$ & $<0.001$ \\
\hline Fasting blood glucose (mmol/l) & $5.6(1.1)$ & $5.3(1.2)$ & $6.0(0.9)$ & $<0.001$ \\
\hline 2-h blood glucose $(\mathrm{mmol} / \mathrm{l})$ & $8.5(2.5)$ & $7.5(1.6)$ & $9.7(3.0)$ & $<0.000$ \\
\hline Physical fitness & $61.0 \%$ & $67.3 \%$ & $52.4 \%$ & 0.036 \\
\hline
\end{tabular}

Mean values (SD). $P$-values for differences between the group with and without MetS are shown (independent sample $t$ test)

a The Metabolic syndrome (MetS): waist circumference $\geq 80 \mathrm{~cm}$, plus any two of the following four factors: serum triglycerides $\geq 1.7 \mathrm{mmol} / \mathrm{L}$, HDL-cholesterol $<1.29 \mathrm{mmol} / 1$, systolic blood pressure $\geq 130 \mathrm{mmHg}$ or diastolic blood pressure $\geq 85 \mathrm{mmHg}$, fasting glucose $\geq 5.6 \mathrm{mmol} / 1$ [1]

${ }^{\mathrm{b}}$ How participants evaluate their knowledge of the Norwegian languish (languish betyr å bli matt/slapp; mener du det, eller språk: language?)

There were no group differences with respect to degree of education, persons in the household, number of children and years living in Norway (Table 1). As expected from the definition, those with MetS had higher BMI (with MetS; $31.2 \pm 5.0$; mean \pm SD, without MetS; $28.3 \pm 5.5$ ) $(P<0.001)$, waist circumference (with MetS; $100 \pm 12.7$, without MetS; $93.1 \pm 11.6)(P<0.001)$ and blood glucose (with MetS; $6.0 \pm 0.9$, without Mets; $5.3 \pm 1.2$ ) $(P<0.001)$ than those without MetS (Table 1$)$.

\section{Self Reported Health}

About one-third of the participants described their general health as good (Table 2). For all eight factors of healthrelated quality of life, the participants scored below 50 .
Especially for physical function (33.9 \pm 23.8 ; mean $\pm \mathrm{SD}$ ), bodily pain $(39.0 \pm 12.6)$ and general health $(34.4 \pm$ 15.2), the scores were very low. The Pakistani women had relatively higher scores on social functioning, role-emotional, and mental health factors (Table 2).

The participants with MetS had significantly lower general health (with MetS; $31.8 \pm 15.5$, without Mets; $36.3 \pm 14.8)(P=0.040)$, lower physical function (with MetS; $29.3 \pm 24.3$, without Mets; $37.8 \pm 22.6)(P=$ 0.012 ), and more bodily pain (with MetS; $36.3 \pm 12.1$, without Mets; $41.2 \pm 12.5) \quad(P=0.007)$, than those without MetS (Table 2). There were no differences between the groups for the SF-36 factors: role-physical, vitality, social functioning, role-emotional, or mental health (Table 2).

Table 2 Adjusted SF-36 factors for the total group of Pakistani immigrant women, and in participants without and with the metabolic syndrome (MetS)

$\begin{array}{lll}\text { Total }(\mathrm{n}=194) & \begin{array}{l}\text { Without MetS } \\ (\mathrm{n}=113)^{\mathrm{a}}\end{array} & \begin{array}{l}\text { With MetS } \\ (\mathrm{n}=81)\end{array}\end{array}$

\begin{tabular}{|c|c|c|c|c|}
\hline \multicolumn{5}{|l|}{$S F-36$} \\
\hline Physical functioning & $33.9(23.8)$ & 37.8 (22.6) & $29.3(24.3)$ & 0.012 \\
\hline Role-physical & $42.0(16.0)$ & $43.6(15.7)$ & $40.2(16.3)$ & 0.148 \\
\hline Bodily pain & $39.0(12.6)$ & $41.2(12.5)$ & $36.3(12.1)$ & 0.007 \\
\hline General health & $34.4(15.2)$ & $36.3(14.8)$ & $31.8(15.5)$ & 0.040 \\
\hline Vitality & $44.7(11.1)$ & $45.5(11.3)$ & $43.8(10.8)$ & 0.287 \\
\hline Social functioning & $49.9(12.9)$ & $51.0(12.0)$ & $48.1(14.0)$ & 0.126 \\
\hline Role-emotional & $48.0(13.4)$ & $48.9(13.1)$ & $46.6(13.8)$ & 0.241 \\
\hline Mental health & $47.2(14.9)$ & $48.0(15.2)$ & $45.9(14.5)$ & 0.343 \\
\hline
\end{tabular}

Mean values (SD). $P$-values for the differences between the group with and without MetS are shown (independent sample $t$ test)

a The Metabolic syndrome (MetS): waist circumference $\geq 80 \mathrm{~cm}$, plus any two of the following four factors: serum triglycerides $\geq 1.7 \mathrm{mmol} / \mathrm{l}$, HDL-cholesterol $<1.29 \mathrm{mmol} / \mathrm{l}$, systolic blood pressure $\geq 130 \mathrm{mmHg}$ or diastolic blood pressure $\geq 85 \mathrm{mmHG}$, fasting glucose $\geq 5.6 \mathrm{mmol} / 1$ [1] 
Table 3 General health, physical fitness, sleep quality, and "ladder of life" for the total group of Pakistani immigrant women, and in subjects without and with the metabolic syndrome (MetS)

\begin{tabular}{|c|c|c|c|c|}
\hline & Total $(\mathrm{n}=198)$ & $\begin{array}{l}\text { Without MetS } \\
(\mathrm{n}=113)^{\mathrm{a}}\end{array}$ & $\begin{array}{l}\text { With MetS } \\
(\mathrm{n}=81)\end{array}$ & $P$-value \\
\hline \multicolumn{5}{|l|}{ Ladder of life } \\
\hline Where are you now? & $6.9(2.1)$ & $6.8(2.2)$ & $7.1(2.1)$ & 0.451 \\
\hline Where were you one year ago? & $6.6(2.4)$ & $6.6(2.4)$ & $6.5(2.5)$ & 0.851 \\
\hline Where are you in one year? & $8.6(1.7)$ & $8.5(1.9)$ & $8.7(1.5)$ & 0.417 \\
\hline
\end{tabular}

Mean values (SD). $P$-values for the differences between the group with and without MetS are shown (independent sample $t$ test)

${ }^{a}$ The Metabolic syndrome (MetS): waist circumference $\geq 80 \mathrm{~cm}$, plus any two of the following four factors: serum triglycerides $\geq 1.7 \mathrm{mmol} / \mathrm{L}$, HDL-cholesterol $<1.29 \mathrm{mmol} / \mathrm{l}$, systolic blood pressure $\geq 130 \mathrm{mmHg}$ or diastolic blood pressure $\geq 85 \mathrm{mmHg}$, fasting glucose $\geq 5.6 \mathrm{mmol} / 1$ [1]

Most participants rated their life as good as measured by the 'ladder of life', and there was a general trend for the participants to be optimistic about their future, however, there were no differences between groups (Table 3). More than half of the participants $(51.5 \%, \mathrm{n}=102)$ expected their life to be at level 9 and 10 on the 'ladder of life' in 1 year time. However, there was no significant correlation between scoring 9 and 10 on the 'ladder of life' and scoring high on the UCL statement question "I tell myself that everything will fix itself at the end".

\section{Subjective Health Complaints}

Almost all participants $(97 \%, \mathrm{n}=192)$ reported to have experienced SHC during the last month, the average was 18 complaints at the same time. Almost 95\% reported musculoskeletal complaints, $83 \%$ reported some pseudoneurological complaint, and $61 \%$ reported gastrointestinal complaints (Table 4). Tiredness, headache, pain in the feet when walking, neck pain, and shoulder pain were the most commonly reported complaints. The MetS group had significantly higher prevalence of shoulder pain, pain in upper back, eczema, extra heartbeats, sleep problems, and depression (Table 4). Particularly for depression, the MetS group showed a very high prevalence $(45.8 \%, \mathrm{n}=83)$, as nearly half of this group reported to have experienced depression during the last month. The MetS group showed a higher total sum-score of SHC $(19.9 \pm 12.9)$, than the group without MetS $(16.7 \pm 12.2)$.

\section{Psychological Distress}

The participants with MetS reported significantly higher levels of somatisation on the Hopkins Symptom Check List (HSCL-25) (Table 5), but there were no significant differences on the depression and anxiety scores between the two groups. A relatively high proportion $(37 \%, \mathrm{n}=73)$ of the participants scored higher than the cut-of points 1.75 for "psychiatric cases" or "severe mental distress", a tendency of more "psychiatric cases" in the MetS group did not reach statistical significance (Table 5).

There was a significant $(P<0.001)$ correlation between the single item depression on the SHC questionnaire and the HSCL-depression score.

\section{Coping}

Palliative reactions and passive avoidance were the two most common coping strategies; however there were no significant differences between the groups for these strategies (Table 6). Also, there were no differences between the groups on social support, depressive reactions, expression of feelings, or comforting thoughts. Participants with MetS scored significantly lower $(P=0.005)$ on active problem solving than participants without MetS (Table 6).

\section{Discussion}

In this group of Pakistani immigrant women we found a high prevalence of psychological distress and SHC, and the participants with Mets scored lower on coping strategies and active problem solving.

We observed a higher prevalence of SHC than previously reported among ethnic Norwegian women [26, 36, 37]. The prevalence of depression was high, and was comparable to the prevalence of depression reported in Norwegian chronic low back pain patients [38]. In addition, there was a high level of psychological distress compared to the general Norwegian population [18, 19, 39], and compared to other Pakistani immigrants [18]. Also for health related quality of life, the Pakistani women scored much lower than the general Norwegian population [40], patients with Rheumatoid Arthritis [41], and patients with neuroendocrine tumours [40].

The relatively high level of complaints may be related at least in part to their low social class, as was also reported from other groups of immigrants in Western Countries 
Table 4 Prevalence of subjective health complaints for the total group of Pakistani immigrant women, and in subjects without and with the metabolic syndrome (MetS)
Differences between groups with and without MetS were tested with chi-square tests, $P$-value given

a The Metabolic syndrome (MetS): waist

circumference $\geq 80 \mathrm{~cm}$, plus any two of the following four factors: serum

triglycerides $\geq 1.7 \mathrm{mmol} / \mathrm{l}$,

HDL-cholesterol $<1.29 \mathrm{mmol} / \mathrm{l}$, systolic blood

pressure $\geq 130 \mathrm{mmHg}$ or

diastolic blood

pressure $\geq 85 \mathrm{mmHg}$, fasting

glucose $\geq 5.6 \mathrm{mmol} / 1[1]$

\begin{tabular}{|c|c|c|c|c|}
\hline & Total $(\mathrm{n}=198)(\%)$ & $\begin{array}{l}\text { Without MetS } \\
(\mathrm{n}=113)^{\mathrm{a}}(\%)\end{array}$ & $\begin{array}{l}\text { With MetS } \\
(\mathrm{n}=81)(\%)\end{array}$ & $P$-value \\
\hline Musculoskeletal complaints & 94.4 & 92.0 & 97.6 & 0.084 \\
\hline Headache & 66.5 & 62.2 & 72.3 & 0.092 \\
\hline Neck pain & 63.6 & 64.3 & 62.7 & 0.466 \\
\hline Shoulder pain & 59.3 & 50.9 & 70.7 & 0.004 \\
\hline Pain in arms & 41.8 & 34.8 & 51.2 & 0.016 \\
\hline Pain in upper back & 35.4 & 31.0 & 41.5 & 0.087 \\
\hline Low back pain & 49.5 & 47.3 & 52.4 & 0.288 \\
\hline Leg pain when walking & 64.8 & 60.2 & 71.1 & 0.076 \\
\hline Migraine & 16.5 & 18.9 & 13.3 & 0.196 \\
\hline Pseudoneurology & 82.7 & 80.5 & 85.5 & 0.236 \\
\hline Extra heartbeats & 27.6 & 21.2 & 36.1 & 0.016 \\
\hline Heat flushes & 13.0 & 8.1 & 19.5 & 0.018 \\
\hline Sleep problems & 32.1 & 27.4 & 38.6 & 0.068 \\
\hline Tiredness & 70.4 & 69.9 & 71.1 & 0.494 \\
\hline Dizziness & 37.2 & 38.9 & 34.9 & 0.337 \\
\hline Anxiety & 31.8 & 30.4 & 33.7 & 0.364 \\
\hline Depression & 38.1 & 32.4 & 45.8 & 0.041 \\
\hline Gastrointestinal complaints & 61.2 & 53.1 & 72.3 & 0.005 \\
\hline Heartburn & 22.2 & 17.9 & 28.0 & 0.066 \\
\hline Stomach discomfort & 7.4 & 4.5 & 11.5 & 0.063 \\
\hline Ulcer/non-ulcer dyspepsia & 5.2 & 4.5 & 6.3 & 0.399 \\
\hline Stomach pain & 15.4 & 13.4 & 18.1 & 0.243 \\
\hline Gas discomfort & 33.7 & 29.2 & 39.8 & 0.082 \\
\hline Diarrhea & 9.2 & 8.0 & 11.0 & 0.318 \\
\hline Obstipation & 30.9 & 31.0 & 30.9 & 0.557 \\
\hline Allergy & 56.1 & 54.0 & 59.0 & 0.288 \\
\hline Asthma & 11.3 & 11.5 & 11.1 & 0.561 \\
\hline Breathing difficulties & 23.1 & 21.2 & 25.6 & 0.293 \\
\hline Eczema & 12.8 & 8.9 & 18.1 & 0.048 \\
\hline Allergy & 24.7 & 23.0 & 27.2 & 0.310 \\
\hline Chest pain & 23.6 & 23.0 & 24.4 & 0.477 \\
\hline Cold/Flu & 49.0 & 46.0 & 53.0 & 0.205 \\
\hline Cough & 32.7 & 31.9 & 33.7 & 0.450 \\
\hline Flu & 35.7 & 32.7 & 39.8 & 0.194 \\
\hline
\end{tabular}

An association between MetS and depression has been described by Dunbay et al. [44], Carroll et al. [45] did not find a similar association, but observed a positive association between anxiety disorders and MetS.

The high level of depression and psychological distress in the MetS group may also relate to their high body weight. Obesity is known to be associated with health problems and depression [46, 47]. Several of the women expressed concerns about their weight [48].

The women with MetS scored lower on active problem solving. Some studies have found that active coping is clearly related to positive metabolic control in men and women with T2D [49-51]. Non-Western immigrants have more negative coping strategies than natives [52-54]. More 
Table 5 Mean values (SD) for Hopkins Symptom CheckList (HSCL) for the total group of Pakistani immigrant women, and in subjects without and with the metabolic syndrome (MetS)

\begin{tabular}{|c|c|c|c|c|}
\hline Hopkins Symptom CheckList (HSCL) & Total $(n=198)$ & Without MetS $(\mathrm{n}=113)$ & MetS $(\mathrm{n}=81)$ & $P$-value \\
\hline HSCL depression & $1.6(0.6)$ & $1.5(0.6)$ & $1.7(0.6)$ & 0.217 \\
\hline HSCL anxiety & $1.6(0.6)$ & $1.6(0.5)$ & $1.7(0.6)$ & 0.166 \\
\hline HSCL somatisation & $1.8(0.8)$ & $1.7(0.6)$ & $1.9(0.7)$ & 0.049 \\
\hline HSCL total & $1.7(0.7)$ & $1.6(0.5)$ & $1.7(0.5)$ & 0.099 \\
\hline HSCL score $\geq 1.75$ psychiatric cases $(\%)$ & $36.9 \%$ & $31.5 \%$ & $43.9 \%$ & 0.078 \\
\hline
\end{tabular}

Differences between the group with and without MetS were tested with independent sample $t$ test, $P$-values given

The Metabolic syndrome (MetS): waist circumference $\geq 80 \mathrm{~cm}$, plus any two of the following four factors: serum triglycerides $\geq 1.7 \mathrm{mmol} / \mathrm{l}$, HDL-cholesterol $<1.29 \mathrm{mmol} / 1$, systolic blood pressure $\geq 130 \mathrm{mmHg}$ or diastolic blood pressure $\geq 85 \mathrm{mmHg}$, fasting glucose $\geq 5.6 \mathrm{mmol} / 1$ [1]

Table 6 Mean scores (SD) for different coping strategies as measured by the Utricht Coping List (UCL) for the total group of Pakistani immigrant women, and in subjects without and with the metabolic syndrome (MetS)

\begin{tabular}{|c|c|c|c|c|}
\hline & Total $(\mathrm{n}=198)$ & Without MetS $(\mathrm{n}=113)$ & With MetS $(\mathrm{n}=81)$ & $P$-value \\
\hline \multicolumn{5}{|l|}{$U C L-C O D E$} \\
\hline Active problem solving & $17.5(4.5)$ & $18.2(4.2)$ & $16.5(4.2)$ & 0.005 \\
\hline Palliative reactions & $19.1(4.2)$ & $19.4(4.3)$ & $18.6(4.0)$ & 0.195 \\
\hline Passive avoidance & $18.9(4.2)$ & $19.1(4.3)$ & $18.6(3.9)$ & 0.439 \\
\hline Social support & $15.2(3.9)$ & $15.6(3.9)$ & $14.7(3.9)$ & 0.125 \\
\hline Depressive reactions & $13.9(3.6)$ & $13.9(3.5)$ & $13.9(3.9)$ & 0.998 \\
\hline Express feelings & $6.9(2.1)$ & $7.0(2.0)$ & $6.8(2.1)$ & 0.516 \\
\hline Comforting thoughts & $14.6(2.7)$ & $14.7(2.7)$ & $14.5(2.6)$ & 0.763 \\
\hline
\end{tabular}

Differences between the group with and without MetS were tested with independent sample $t$ test, $P$-values given

The Metabolic syndrome (MetS): waist circumference $\geq 80 \mathrm{~cm}$, plus any two of the following four factors: serum triglycerides $\geq 1.7 \mathrm{mmol} / 1$, HDL-cholesterol $<1.29 \mathrm{mmol} / \mathrm{l}$, systolic blood pressure $\geq 130 \mathrm{mmHg}$ or diastolic blood pressure $\geq 85 \mathrm{mmHg}$, fasting glucose $\geq 5.6 \mathrm{mmol} / 1$ [1]

distressful coping strategies such as fatalism, resignation, isolation, and intrusion, in immigrants with MetS have been reported earlier [52]. The psychobiological responses and effect on health in individuals depend on the expectancies attached to the coping skills of the individual [20], and at least part of the pathophysiological findings may be related to inefficient coping. Poor language skills, physical inactivity, increased body weight, and a high level of SHC suggest that the Pakistani women have problems with mood and motivation to adjust to life in Norway.

In addition to the general and well-accepted risk factors for $\mathrm{T} 2 \mathrm{D}$, there are other possible factors that may contribute substantially to their risk of developing T2D. This includes the experience of higher demands due to strained psychosocial conditions [27] in combination with less coping resources. Lack of coping may cause ill health thru the general "psychosomatic route" with sustained activation followed by disease and illness. Establishing no or negative response outcome expectancies may also be a hindrance for the engagement in behavioral changes such as e physical activity and eating habits [55].

The high body weight, their lack of adaptation to the new life conditions, and the potential pathophysiological effects of a sustained psychophysiological activation are serious risk factors for further complications arising from the MetS condition, such as T2D and cardiovascular diseases. Stress activation is followed by increased serum levels of glucose, free fatty acids and lipoproteins, all of which increase the risk of cardiovascular diseases [22].

The recruitment strategy used in the present work could lead to selection bias. Although the present combination of several strategies to recruit participants produced a sufficient number of participants, we have no way of stating anything about non-participants. Our multi-strategic recruitment method may reduce the selection bias as women were recruited from several different arenas. The quality of the data rests on the assumption that the sample obtained is a representative sample of the target population, and that willingness to participate is unrelated to opinions that are sampled. Additionally, our cross-sectional design does not allow any conclusions regarding causation.

Information bias could be a major issue in this study group, due to the several languages spoken and the need to use interpreters to access the data. To prevent information bias we used several different interpreters, as well as crosstesting of the information given. 
Questionnaires were not translated into Urdu, Punjabi or English, and communication with the participants was obtained through interpreters, and by having a third person knowing all languages to observe several of the interviews. Nevertheless, the possibility exists that there might have been some bias in the information flow from the investigators to the respondents. To minimize the problem, all interviewers were multilingual, grown up and living in two cultures, and speaking the languages in question very well. Ideally, the women should have had the opportunity to read for themselves, but most of our participants were not sufficiently literate. The confidentiality for the participants might have been a problem. However, the interviewers and the observers were from different areas in Oslo, and from different social classes.

\section{Conclusion}

We found a high prevalence of MetS, psychological distress and SHC in a group of Pakistani immigrant women, especially in subjects with MetS. This group should be given special attention when developing public and individual preventive strategies for T2D.

\section{New Contribution to the Literature}

The study provides an update of the prevalence of MetS, psychological stress and SHC among female Pakistani immigrants living in Norway, and confirms that psychological distress is associated with MetS.

Conflict of Interest The authors declare no conflict of interest. Many people have contributed in different stages of the project. We want especially to thank Monica Morris, Aisha Ashgar Ali, Anica Munir, Marianne Lunde, Eva Kristiansen, and all the participating women who gave us of their time and shared their knowledge and experiences with us.

Open Access This article is distributed under the terms of the Creative Commons Attribution Noncommercial License which permits any noncommercial use, distribution, and reproduction in any medium, provided the original author(s) and source are credited.

\section{References}

1. Koehn PH. Globalization, migration health, and educational preparation for transnational medical encounters. Global Health. 2006;2:2.

2. Mather HM, Keen H. The southall diabetes survey: prevalence of known diabetes in Asians and Europeans. Br Med J (Clin Res Ed). 1985;291:1081-4.

3. Alberti KG, Zimmet P, Shaw J. Metabolic syndrome-a new world-wide definition. A consensus statement from the international diabetes federation. Diabet Med. 2006;23:469-80.
4. Alberti KG, Zimmet P, Shaw J. The metabolic syndrome-a new worldwide definition. Lancet. 2005;366:1059-62.

5. Mbanya J-C, Gan D, Allgot B, Bakker K, Brown JB, Roglic G, et al. The metabolic syndrome. In Diabetes atlas. International Diabetes Federation; 2006. p. 307-313.

6. Bhopal R, Hayes L, White M, Unwin N, Harland J, Ayis S, et al. Ethnic and socio-economic inequalities in coronary heart disease, diabetes and risk factors in Europeans and South Asians. J Public Health Med. 2002;24:95-105.

7. Jenum AK, Holme I, Graff-Iversen S, Birkeland KI. Ethnicity and sex are strong determinants of diabetes in an urban Western society: implications for prevention. Diabetologia. 2005;48:435-9.

8. Reaven P. Metabolic syndrome. J Insur Med. 2004;36:132-42.

9. Jafar TH, Chaturvedi N, Pappas G. Prevalence of overweight and obesity and their association with hypertension and diabetes mellitus in an Indo-Asian population. CMAJ. 2006;175:1071-7.

10. Kolsgaard ML, Andersen LF, Tonstad S, Brunborg C, Wangensteen T, Joner G. Ethnic differences in metabolic syndrome among overweight and obese children and adolescents: the Oslo adiposity intervention study. Acta Paediatr. 2008;97:1557-63.

11. Wandell PE, Gafvels C. High prevalence of diabetes among immigrants from non-European countries in Sweden. Prim Care Diabetes. 2007;1:13-6.

12. Zimmet P, Alberti KG, Shaw J. Global and societal implications of the diabetes epidemic. Nature. 2001;414:782-7.

13. Lindstrom M, Sundquist J. Immigration and leisure-time physical inactivity: a population-based study. Ethn Health. 2001;6:77-85.

14. Wandel M, Raberg M, Kumar B, Holmboe-Ottesen G. Changes in food habits after migration among South Asians settled in Oslo: the effect of demographic, socio-economic and integration factors. Appetite. 2008;50:376-85.

15. Blom S, Henriksen K. Levekår blandt innvandrere i Norge 2005/ 2006. Statistics Norway; 2008.

16. Dalgard OS, Mykletun A, Rognerud M, Johansen R, Zahl PH. Education, sense of mastery and mental health: results from a nation wide health monitoring study in Norway. BMC Psychiatry. 2007;7:20.

17. Thapa SB, Dalgard OS, Claussen B, Sandvik L, Hauff E. Psychological distress among immigrants from high- and lowincome countries: findings from the Oslo health study. Nord J Psychiatry. 2007;61:459-65.

18. Syed HR, Dalgard OS, Dalen I, Claussen B, Hussain A, Selmer $\mathrm{R}$, et al. Psychosocial factors and distress: a comparison between ethnic Norwegians and ethnic Pakistanis in Oslo, Norway. BMC Public Health. 2006;6:182.

19. Syed HR, Dalgard OS, Hussain A, Dalen I, Claussen B, Ahlberg NL. Inequalities in health: a comparative study between ethnic Norwegians and Pakistanis in Oslo, Norway. Int J Equity Health. 2006;5:7.

20. Ursin H, Eriksen HR. The cognitive activation theory of stress. Psychoneuroendocrinology. 2004;29:567-92.

21. Kristenson M, Eriksen HR, Sluiter JK, Starke D, Ursin H. Psychobiological mechanisms of socioeconomic differences in health. Soc Sci Med. 2004;58:1511-22.

22. Vander A, Sherman J, Luciano D. Human physiology. McGrawHill International Edition; 2001.

23. Temelkova-Kurktschiev TS, Koehler C, Henkel E, Leonhardt W, Fuecker K, Hanefeld M. Postchallenge plasma glucose and glycemic spikes are more strongly associated with atherosclerosis than fasting glucose or HbA1c level. Diabetes Care. 2000;23: 1830-4.

24. Eriksen HR, Ursin H. Social inequalities in health: biological, cognitive and learning theory perspectives. Norsk Epidemiologi. 2002;12(1):33-8.

25. Hjellset VT, Bjørge B, Eriksen HR, Høstmark AT. Risk factors for type 2 diabetes among female Pakistani immigrants: the 
InvaDiab-DEPLAN study on Pakistani immigrant women living in Oslo, Norway. J Immigrant Minority Health. 2009. doi:10.1007/s10903-009-9290-3.

26. Ihlebaek C, Eriksen HR, Ursin H. Prevalence of subjective health complaints (SHC) in Norway. Scand J Public Health. 2002;30: 20-9.

27. Soares JJ, Grossi G. Experience of musculoskeletal pain. Comparison of immigrant and Swedish patient. Scand J Caring Sci. 1999; 13:254-66.

28. Heraclides A, Chandola T, Witte DR, Brunner EJ. Psychosocial stress at work doubles the risk of type 2 diabetes in middle-aged women: evidence from the Whitehall II study. Diabetes Care. 2009;32:2230-5.

29. ICPC-2 International Classification of Primary Care. 2004.

30. Kumar BN, Meyer HE, Wandel M, Dalen I, Holmboe-Ottesen G. Ethnic differences in obesity among immigrants from developing countries, in Oslo, Norway. Int J Obes (Lond). 2006;30:684-90.

31. Hussain-Gambles M, Leese B, Atkin K, Brown J, Mason S, Tovey P. Involving South Asian patients in clinical trials. Health Technol Assess. 2004;8:iii, 1-iii109.

32. Ware JE Jr, Sherbourne CD. The MOS 36-item short-form health survey (SF-36). I. Conceptual framework and item selection. Med Care. 1992;30:473-83.

33. Loge JH, Kaasa S. Short form 36 (SF-36) health survey: normative data from the general Norwegian population. Scand J Soc Med. 1998;26:250-8.

34. Loge JH, Kaasa S, Hjermstad MJ, Kvien TK. Translation and performance of the Norwegian SF-36 Health Survey in patients with rheumatoid arthritis. I. Data quality, scaling assumptions, reliability, and construct validity. J Clin Epidemiol. 1998;51: 1069-76.

35. Craig CL, Marshall AL, Sjostrom M, Bauman AE, Booth ML, Ainsworth BE, et al. International physical activity questionnaire: 12-country reliability and validity. Med Sci Sports Exerc. 2003;35:1381-95.

36. Tveito TH, Passchier J, Duivenvoorden HJ, Eriksen HR. Subjective health complaints and health related quality of life in a population of health care workers. Psychology and Health. 2004;19:247-59.

37. Ihlebaek C, Brage S, Eriksen HR. Health complaints and sickness absence in Norway, 1996-2003. Occup Med (Lond). 2007;57: 43-9.

38. Hagen EM, Svensen E, Eriksen HR, Ihlebaek CM, Ursin H. Comorbid subjective health complaints in low back pain. Spine. 2006;31:1491-5.

39. Sandanger I, Nygard JF, Sorensen T, Moum T. Is women's mental health more susceptible than men's to the influence of surrounding stress? Soc Psychiatry Psychiatr Epidemiol. 2004;39:177-84.

40. Haugland T, Vatn MH, Veenstra M, Wahl AK, Natvig GK. Health related quality of life in patients with neuroendocrine tumors compared with the general Norwegian population. Qual Life Res. 2009;18:719-26.

41. Kvien TK, Kaasa S, Smedstad LM. Performance of the Norwegian SF-36 health survey in patients with rheumatoid arthritis. II.
A comparison of the SF-36 with disease-specific measures. J Clin Epidemiol. 1998;51:1077-86.

42. Chichlowska KL, Rose KM, ez-Roux AV, Golden SH, McNeill AM, Heiss G. Life course socioeconomic conditions and metabolic syndrome in adults: the Atherosclerosis Risk in Communities (ARIC) Study. Ann Epidemiol. 2009;19:875-83.

43. Raikkonen K, Matthews KA, Kuller LH. The relationship between psychological risk attributes and the metabolic syndrome in healthy women: antecedent or consequence? Metabolism. 2002;51:1573-7.

44. Dunbar JA, Reddy P, vis-Lameloise N, Philpot B, Laatikainen T, Kilkkinen A, et al. Depression: an important comorbidity with metabolic syndrome in a general population. Diabetes Care. 2008;31:2368-73.

45. Carroll D, Phillips AC, Thomas GN, Gale CR, Deary I, Batty GD. Generalized anxiety disorder is associated with metabolic syndrome in the Vietnam experience study. Biol Psychiatry. 2009;66: 91-3.

46. Pi-Sunyer X. The medical risks of obesity. Postgrad Med. 2009;121:21-33.

47. Algul A, Ates MA, Semiz UB, Basoglu C, Ebrinc S, Gecici O, et al. Evaluation of general psychopathology, subjective sleep quality, and health-related quality of life in patients with obesity. Int J Psychiatry Med. 2009;39:297-312.

48. Hussain A, Bjørge B, Hjellset VT, Holmboe-Ottesen G, Wandel M. Body size perceptions among Pakistani women in Norway participating in a controlled trial to prevent deterioration of glucose tolerance. Ethnicity and Health. 2010;Apr 7:1-15.

49. Turan B, Osar Z, Molzan TJ, Damci T, Ilkova H. The role of coping with disease in adherence to treatment regimen and disease control in type 1 and insulin treated type 2 diabetes mellitus. Diabetes Metab. 2002;28:186-93.

50. Rose M, Fliege H, Hildebrandt M, Schirop T, Klapp BF. The network of psychological variables in patients with diabetes and their importance for quality of life and metabolic control. Diabetes Care. 2002;25:35-42.

51. Gafvels C, Wandell PE. Coping strategies in men and women with type 2 diabetes in Swedish primary care. Diabetes Res Clin Pract. 2006;71:280-9.

52. Gafvels C, Wandell PE. Coping strategies in immigrant men and women with type 2 diabetes. Diabetes Res Clin Pract. 2007; 76:269-78.

53. Wandell PE, Gafvels C. Patients with type 2 diabetes aged 35-64 years at four primary health care centres in Stockholm County, Sweden. Prevalence and complications in relation to gender and socio-economic status. Diabetes Res Clin Pract. 2004;63: 195-203.

54. Dalgard OS, Thapa SB. Immigration, social integration and mental health in Norway, with focus on gender differences. Clin Pract Epidemol Ment Health. 2007;3:24.

55. Eriksen HR, Murison R, Pensgaard AM, Ursin H. Cognitive activation theory of stress (CATS): from fish brains to the Olympics. Psychoneuroendocrinology. 2005;30:933-8. 